\title{
Internal tide energy flux over a ridge measured by a co-located ocean glider and moored acoustic Doppler current profiler
}

\author{
Rob A. Hall ${ }^{1}$, Barbara Berx ${ }^{2}$, and Gillian M. Damerell ${ }^{1}$ \\ ${ }^{1}$ Centre for Ocean and Atmospheric Sciences, School of Environmental Sciences, \\ University of East Anglia, Norwich Research Park, Norwich, NR4 7TJ, UK \\ ${ }^{2}$ Marine Scotland Science, Marine Laboratory, 375 Victoria Road, Aberdeen, AB11 9DB, UK
}

Correspondence: Rob A. Hall (robert.hall@uea.ac.uk)

Received: 28 February 2019 - Discussion started: 5 March 2019

Revised: 22 May 2019 - Accepted: 3 June 2019 - Published: 7 November 2019

\begin{abstract}
Internal tide energy flux is an important diagnostic for the study of energy pathways in the ocean, from large-scale input by the surface tide to small-scale dissipation by turbulent mixing. Accurate calculation of energy flux requires repeated full-depth measurements of both potential density $(\rho)$ and horizontal current velocity $(\boldsymbol{u})$ over at least a tidal cycle and over several weeks to resolve the internal spring-neap cycle. Typically, these observations are made using full-depth oceanographic moorings that are vulnerable to being "fished out" by commercial trawlers when deployed on continental shelves and slopes. Here we test an alternative approach to minimize these risks, with $\boldsymbol{u}$ measured by a low-frequency acoustic Doppler current profiler (ADCP) moored near the seabed and $\rho$ measured by an autonomous ocean glider holding station by the ADCP. The method is used to measure the semidiurnal internal tide radiating from the Wyville Thomson Ridge in the North Atlantic. The observed energy flux $\left(4.2 \pm 0.2 \mathrm{~kW} \mathrm{~m}^{-1}\right)$ compares favourably with historic observations and a previous numerical model study.

Error in the energy flux calculation due to imperfect colocation of the glider and ADCP is estimated by subsampling potential density in an idealized internal tide field along pseudorandomly distributed glider paths. The error is considered acceptable $(<10 \%)$ if all the glider data are contained within a "watch circle" with a diameter smaller than $1 / 8$ the mode1 horizontal wavelength of the internal tide. Energy flux is biased low because the glider samples density with a broad range of phase shifts, resulting in underestimation of vertical isopycnal displacement and available potential energy. The negative bias increases with increasing watch circle diameter.
\end{abstract}

If watch circle diameter is larger than $1 / 8$ the mode- 1 horizontal wavelength, the negative bias is more than $3 \%$ and all realizations within the $95 \%$ confidence interval are underestimates. Over the Wyville Thomson Ridge, where the semidiurnal mode- 1 horizontal wavelength is $\approx 100 \mathrm{~km}$ and all the glider dives are within a $5 \mathrm{~km}$ diameter watch circle, the observed energy flux is estimated to have a negative bias of only $0.4 \%$ and an error of less than $3 \%$ at the $95 \%$ confidence limit. With typical glider performance, we expect energy flux error due to imperfect co-location to be $<10 \%$ in most mid-latitude shelf slope regions.

\section{Introduction}

Internal tides are a ubiquitous hydrodynamic feature over continental shelves and slopes as they are commonly generated at the shelf break by across-slope tidal flows (Baines, 1982; Pingree et al., 1986; Sharples et al., 2007). However, direct measurement of internal tides can be a challenge in these regions due to intense commercial fishing activity leading to an increased risk of oceanographic mooring loss (Sharples et al., 2013). Calculation of internal tide energy flux, a key diagnostic for the understanding of baroclinic energy pathways, requires repeated full-depth measurements of both potential density $(\rho)$ and horizontal current velocity $(\boldsymbol{u})$ over at least a tidal cycle (Nash et al., 2005). If an objective is to resolve the internal spring-neap cycle or observe the effect of seasonal changes in stratification on the internal tide field, repeated full-depth measurements over several weeks or months are required. Typically, these measurements 
are made using a full-depth oceanographic mooring incorporating an acoustic Doppler current profiler (ADCP) and a string of conductivity-temperature loggers (e.g. Hopkins et al., 2014), or a profiling mooring with a CTD (conductivity, temperature, and depth) and acoustic current meter (e.g. Zhao et al., 2012). On continental shelves and slopes, these full-depth moorings are vulnerable to being "fished out" by demersal and pelagic trawling activity.

Hall et al. (2017b) describe a novel alternative approach to minimize these risks, with $\boldsymbol{u}$ measured by a low-frequency ADCP moored near the seabed and $\rho$ measured by an autonomous ocean glider holding station by the ADCP as a "virtual mooring". Commercial fishing activity on continental shelves and their adjacent slopes is often intense because these regions are highly biologically productive. However, steps can be taken to reduce the risk of ADCP loss, including deploying deeper than $600 \mathrm{~m}$, keeping mooring lines short, or using trawl-resistant frames. Being relatively small, gliders are unlikely to be fished out, and the risk can be further reduced by real-time evasive action in response to vessel proximity guided by the maritime automatic identification system (AIS). However, this alternate approach was not comprehensively tested by Hall et al. (2017b) because of glider navigation and telemetry problems. In this study we test the method using a co-located glider and ADCP dataset from the Wyville Thomson Ridge in the North Atlantic, a topographic feature that previous observations and numerical model studies suggest is an energetic internal tide generator (Sherwin, 1991; Hall et al., 2011). We also estimate the error in the energy flux calculation due to imperfect co-location of the glider and ADCP and find that, with typical glider performance, it is acceptable in most mid-latitude shelf slope regions.

Ocean gliders have previously been used to observe internal waves and internal tides (Rudnick et al., 2013; Rainville et al., 2013; Johnston and Rudnick, 2015; Boettger et al., 2015; Hall et al., 2017a), including the calculation of energy fluxes using current velocity measurements from gliders equipped with ADCPs (Johnston et al., 2013, 2015). However, ADCPs are not routinely integrated with commercially available glider platforms (Seaglider, Slocum, and SeaExplorer), in part due to their higher power requirement. Synergy with moored ADCP data allows accurate calculation of internal tide energetics without the endurance limitations and data analysis complexities of an ADCP-equipped glider (e.g. Todd et al., 2017).

In Sect. 2 the temporal resolution constraints of glider measurements are explained and the observations used in this study described. The calculation of internal tide energy flux from co-located glider and moored ADCP data is fully described in Sect. 3. Observations of the internal tide radiating from the Wyville Thomson Ridge are presented in Sect. 4 and compared with historic observations and a previous numerical model study. In Sect. 5 the error in the energy flux calculation due to imperfect co-location is estimated. Key results are summarized and discussed in Sect. 6.

\section{Observations}

High temporal resolution is crucial for internal tide observations; Nash et al. (2005) suggest that a minimum of four evenly distributed independent profiles of $\boldsymbol{u}$ and $\rho$ are required per tidal cycle for an unbiased calculation of energy flux. Over continental shelves and upper shelf slopes, this temporal resolution is achievable using gliders. Typical glider vertical velocities are $15-20 \mathrm{~cm} \mathrm{~s}^{-1}$, so a complete dive cycle to $1000 \mathrm{~m}$ can take as little as $3 \mathrm{~h}$. This yields eight profiles (four dives) per semidiurnal $(\approx 12 \mathrm{~h}$ ) tidal cycle, but near the surface and seabed the descending and ascending profiles converge in time so the number of independent samples is halved to four. For diurnal $(\approx 24 \mathrm{~h})$ internal tides, 16 profiles per cycle are possible. In shallower water the temporal resolution of glider measurements increases further; $40 \mathrm{~min}$ full-depth dives are achievable over a $200 \mathrm{~m}$ deep shelf break, yielding 36 profiles per semidiurnal tidal cycle. The depth-limiting factor of the methodology is the range of the ADCP. In narrowband mode, $75 \mathrm{kHz}$ ADCPs have a maximum range of around $600 \mathrm{~m}$ (dependent on environmental conditions) so multiple ADCPs or additional current meters on the mooring line are required for sites between 600 and $1000 \mathrm{~m}$ deep.

The observations used to test the method were collected from the northern flank of the Wyville Thomson Ridge (WTR) in the North Atlantic (Fig. 1a). A Kongsberg Seaglider (SG613; Eriksen et al., 2001) was deployed from NRV Alliance between 2 and 5 June 2017 during the fourth Marine Autonomous Systems in Support of Marine Observations mission (MASSMO4). The glider was navigated from the deeper waters of the Faroe-Shetland Channel (FSC) to the WTR and held station for $40 \mathrm{~h}$ by a short oceanographic mooring, deployed 5 days previously from MRV Scotia (Fig. 1b). The mooring was sited close to the $800 \mathrm{~m}$ isobath and instrumented with an upwards-looking $75 \mathrm{kHz}$ RDI Long Ranger ADCP at approximately $722 \mathrm{~m}$ and an Aanderaa Seaguard acoustic current meter at $784 \mathrm{~m}$, yielding observations of horizontal current velocity over $78 \%$ of the water column. When on-station by the ADCP mooring, the glider made repeated $2 \mathrm{~h}$ dives to $700 \mathrm{~m}$ or the seabed, whichever was shallower. This yielded approximately 12 profiles (six independent samples near the surface and seabed; 12 independent samples at mid-depth) per semidiurnal tidal cycle.

Glider location at the surface, before and after each dive, was given by GPS position. Subsurface sample locations were approximated by linearly interpolating surface latitude and longitude onto sample time. When on-station, the glider stayed within $2.5 \mathrm{~km}$ of the mooring and the mean horizontal distance between temporally coincident glider and ADCP measurements was $1.3 \mathrm{~km}$. This spatial scattering of the glider data is small compared to the semidiurnal mode- 1 horizontal wavelength over the WTR $(\approx 100 \mathrm{~km}$, calculated from the observed buoyancy frequency profile) and so the 

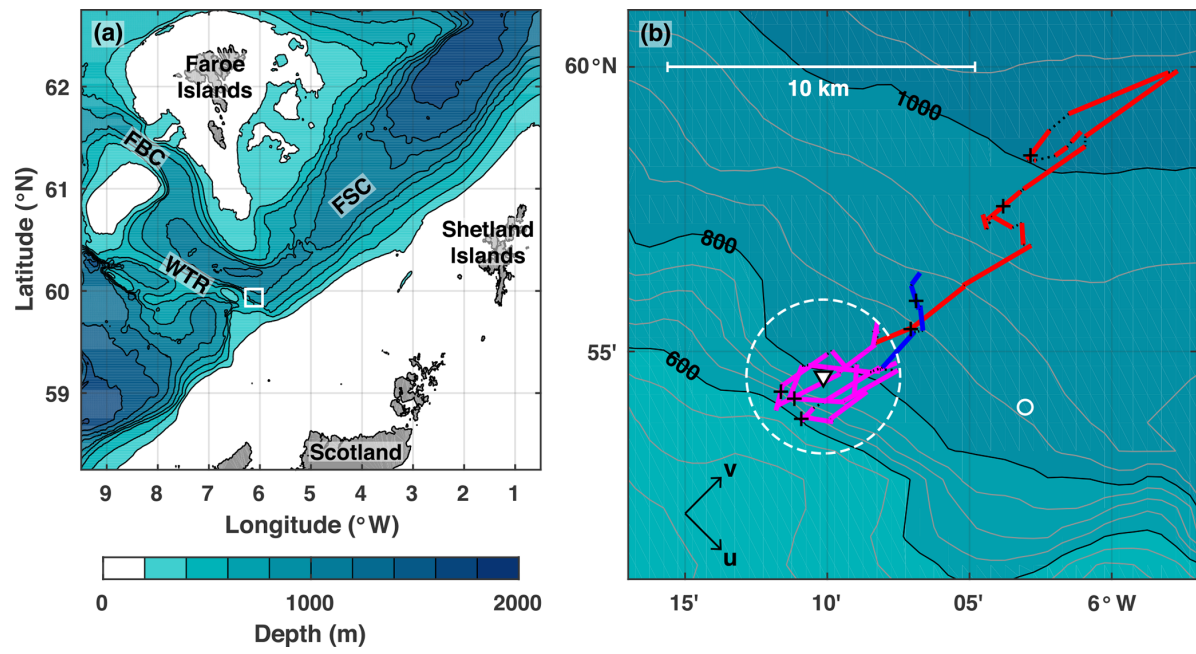

Figure 1. (a) Location of the experiment site (white square) and regional bathymetry, including the Faroe Bank Channel (FBC), FaroeShetland Channel (FSC), and Wyville Thomson Ridge (WTR). (b) Path of the glider over the WTR with local bathymetry ( $\Delta 50 \mathrm{~m}$ isobaths in grey). Dives are separated into deployment (red), on-station (magenta), and recovery (blue) sections with a black cross every $12 \mathrm{~h}$ (00:00 and 12:00 UTC). The dotted black lines are surface drift. The white triangle is the location of the ADCP mooring and the dashed white line delineates a $5 \mathrm{~km}$ diameter "watch circle" around it. The white circle is the location of the CTD repeat station where Sherwin (1991) observed a semidiurnal internal tide. The bathymetric dataset is the GEBCO 201430 arcsec grid (http://www.gebco.net, last access: 25 March 2015).

glider data are initially considered a fixed-point time series with no spatial-temporal aliasing.

As the glider was on-station for only $40 \mathrm{~h}$, the co-located time series is not long enough to resolve the internal springneap cycle. As a result, $M_{2}$ harmonic fits to the glider and mooring data (Sect. 3) are contaminated with $S_{2}$ variability. To acknowledge this, we refer to the estimated $M_{2}$ component of the co-located time series as $D_{2}$ following Alford et al. (2011). The comparative numerical model (Sect. 4.1) only includes the $M_{2}$ tidal constituent so we refer to model diagnostics as $M_{2}$.

\subsection{Data processing}

The glider was equipped with a standard Sea-Bird Electronics conductivity-temperature (CT) sail sampling at $0.2 \mathrm{~Hz}$ and the data processed using the UEA Seaglider Toolbox (https://bitbucket.org/bastienqueste/uea-seaglider-toolbox, last access: 9 February 2017) following Queste (2014). Conductivity data were corrected for thermal hysteresis following Garau et al. (2011) and the Seaglider flight model regressed using a method adapted from Frajka-Williams et al. (2011). As the CT sail was unpumped, salinity samples were flagged when the glider's speed was less than $10 \mathrm{~cm} \mathrm{~s}^{-1}$ or it was within $8 \mathrm{~m}$ of apogee ${ }^{1}$. Temperature-salinity profiles from descents and ascents were independently averaged (median value) in $5 \mathrm{~m}$ depth bins, typically with 4-5 samples

\footnotetext{
${ }^{1}$ Apogee is the phase of the dive between descent and ascent, when the glider pitches upwards and increases its buoyancy. Flow through the conductivity cell is unpredictable during this phase and so salinity spikes are common.
}

per bin. Sample time was averaged into the same bins to allow accurate temporal analysis at all depths. Absolute Salinity $\left(S_{\mathrm{A}}\right)$, Conservative Temperature $(\Theta)$, and potential density $(\rho)$ in each bin were calculated using the TEOS-10 equation of state (IOC et al., 2010).

The $75 \mathrm{kHz}$ ADCP was configured in narrowband mode with $10 \mathrm{~m}$ bins and 24 pings per $20 \mathrm{~min}$ ensemble. The ADCP data were processed using Marine Scotland Science's standard protocols, including correction for magnetic declination and quality assurance based on error velocity, vertical velocity, and percentage good ping thresholds. The ADCP data were then linearly upsampled onto the same $\Delta 5 \mathrm{~m}$ depth levels as the glider data. The acoustic current meter was configured with a $10 \mathrm{~min}$ sampling interval and linearly downsampled onto the same 20 min sampling interval as the ADCP. Good velocity data were recovered for all depth levels between 85 and $705 \mathrm{~m}$, as well as 780-785 m. In addition to the ADCP and current meter measurements, horizontal velocity was inferred from GPS position and the Seaglider flight model using a dive-average current method (DAC; Eriksen et al., 2001; Frajka-Williams et al., 2011). DAC was only calculated for dives deeper than $500 \mathrm{~m}$ so that values were representative of the majority of the water column. All velocities were transformed into along-slope and across-slope components. We take the northern flank of the WTR to be orientated exactly northwest-southeast so along-slope $(u)$ is positive southeast and across-slope $(v)$ is positive northeast (down-slope).

The full 3-day glider time series of Conservative Temperature and Absolute Salinity is shown in Fig. 2a. A semidiurnal internal tide is evident as a vertical oscillation of the main 

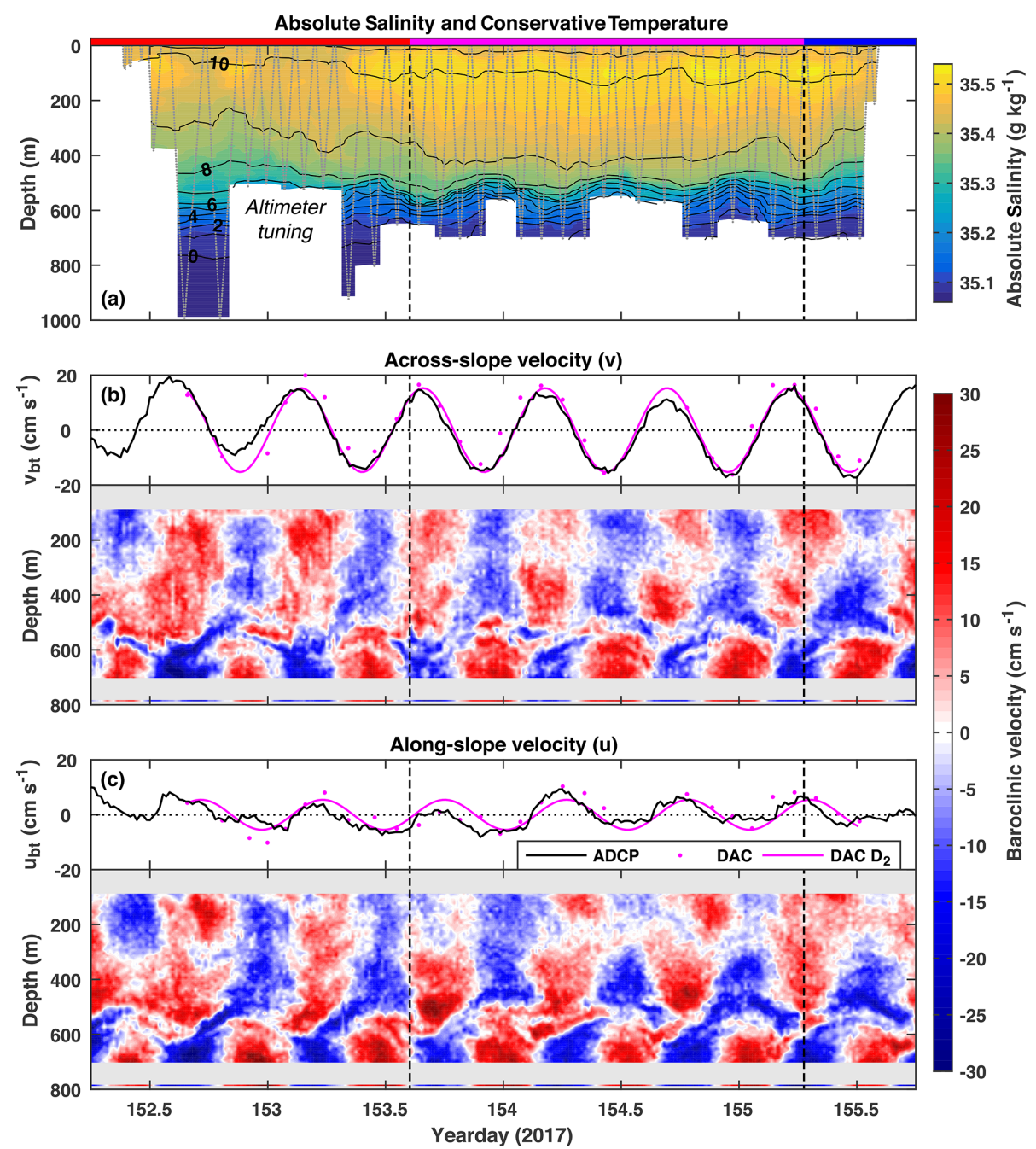

Figure 2. (a) Absolute Salinity (colour) and Conservative Temperature (black contours, interval: $1^{\circ} \mathrm{C}$ ) measured by the glider. The dotted grey line is the glider's path and shows the temporal sampling resolution. The magenta section is when the glider was on-station by the ADCP mooring. (b) Across-slope barotropic (black line) and baroclinic (colour) velocities measured by the ADCP and current meter and dive-average current (DAC) velocity inferred from the glider (magenta dots). The magenta line is a $D_{2}$ harmonic fit to DAC velocity. Positive velocities are northeast (down-slope). Panel (c) is the same as (b) but for along-slope velocities. Positive velocities are southeast.

pycnocline (centred around $550 \mathrm{~m}$ ) with an amplitude up to $50 \mathrm{~m}$ and a period of $\approx 12 \mathrm{~h}$. Temporally coincident ADCP and current meter measurements (Fig. 2b, c) show dominant semidiurnal periodicity and a reversal of baroclinic current velocity across the main pycnocline, characteristic of a lowmode internal tide. Mode-1 horizontal velocity, calculated from the observed buoyancy frequency profile, reverses at approximately $505 \mathrm{~m}$, slightly above the pycnocline.

\section{Internal tide energy flux}

Following Kunze et al. (2002) and Nash et al. (2005), internal tide energy flux is calculated as $\boldsymbol{F}=\left\langle\boldsymbol{u}_{\mathrm{bc}}^{\prime} p^{\prime}\right\rangle$. The method requires repeated full-depth measurements of $\rho$ and $\boldsymbol{u}$ over at least a tidal cycle in order to determine pressure perturbation $\left(p^{\prime}\right)$ and baroclinic velocity $\left(\boldsymbol{u}_{\mathrm{bc}}^{\prime}\right)$, respectively.

\subsection{Pressure perturbation}

For the $40 \mathrm{~h}$ window when the glider was on-station by the ADCP mooring, potential density anomaly is calculated by subtracting the window-mean density profile from measured potential density,

$\rho^{\prime}(z, t)=\rho(z, t)-\bar{\rho}(z)$.

Before subtraction, $\bar{\rho}(z)$ is smoothed with a $50 \mathrm{~m}$ gaussian tapered running mean $(\sigma=10 \mathrm{~m})$ to yield a suitable background density profile. Vertical isopycnal displacement is 

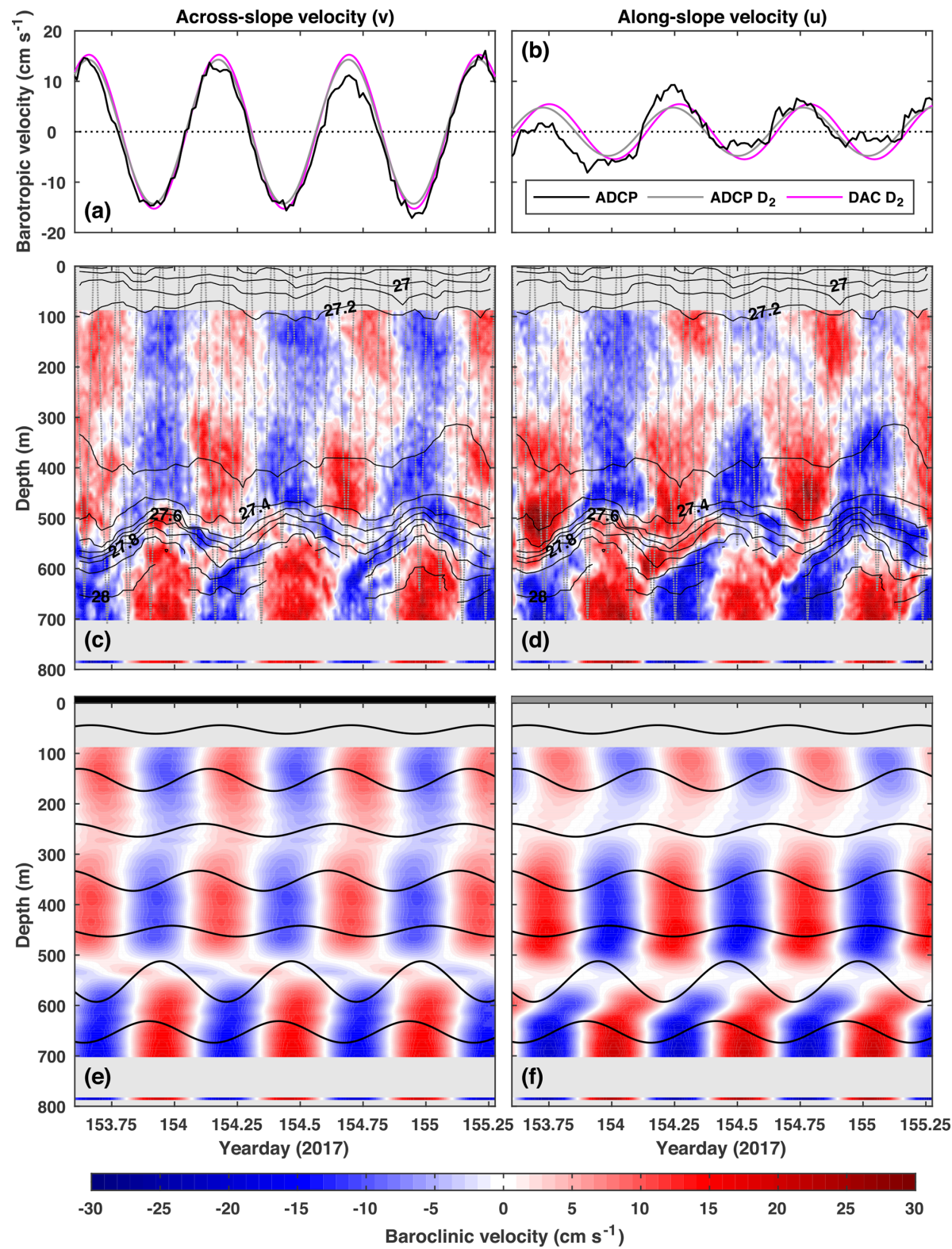

Figure 3. (a) Across-slope barotropic velocity (black), the $D_{2}$ component (grey), and a $D_{2}$ harmonic fit to DAC velocity (magenta). (c) Across-slope baroclinic velocity (colour) overlaid with potential density (black contours, interval: $0.1 \mathrm{~kg} \mathrm{~m}^{-3}$ ). (e) The $D_{2}$ component of across-slope baroclinic velocity (colour) overlaid with the $D_{2}$ component of vertical isopycnal displacement every $100 \mathrm{~m}$ (black lines). Panels (b), (d), and (f) are the same as (a), (c), and (e) but for along-slope velocities.

then calculated as

$\xi(z, t)=-\rho^{\prime}(z, t)\left(\frac{\partial \bar{\rho}}{\partial z}\right)^{-1}$.

To separate $D_{2}$ internal tide variability from other physical processes, $M_{2}$ tidal period $(T=12.42 \mathrm{~h})$ harmonics are fit to $\xi$ on each $\Delta 5 \mathrm{~m}$ depth level following Emery and Thomson (2001). This analysis is only applied to depth levels between 10 and $675 \mathrm{~m}$; near-surface and near-bottom bins are excluded because of high numbers of flagged samples and reduced temporal resolution due to the glider going into apogee above $700 \mathrm{~m}$. To obtain a full-depth time series, the $D_{2} \mathrm{com}$ ponent of $\xi$ is linearly extrapolated assuming $\xi=0$ at the surface $(z=0)$ and bottom $(z=-H$, where $H$ is water depth). Buoyancy frequency squared, $N^{2}=-g / \rho_{0}(\partial \bar{\rho} / \partial z)$, is also linearly extrapolated, assuming $N^{2}=10^{-6} \mathrm{~s}^{-2}$ at the surface and bottom. Pressure perturbation is then calculated by integrating the hydrostatic equation from the surface,

$p^{\prime}(z, t)=p_{\text {surf }}^{\prime}(t)+\rho_{0} \int_{z}^{0} N^{2}(z) \xi(z, t) \mathrm{d} z$, 

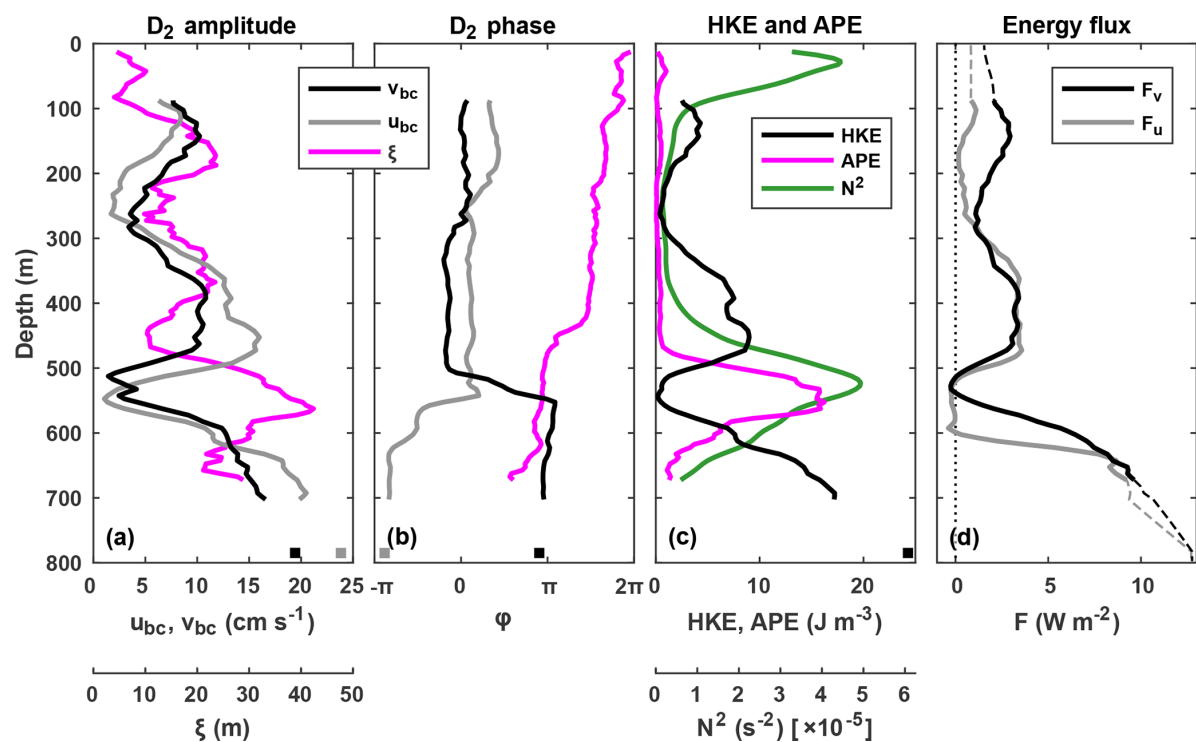

Figure 4. (a) Amplitude and (b) phase of the $D_{2}$ components of across-slope baroclinic velocity (black), along-slope baroclinic velocity (grey), and vertical isopycnal displacement (magenta). (c) Horizontal kinetic energy (black), available potential energy (magenta), and buoyancy frequency squared (green). (d) Across-slope (black) and along-slope (grey) $D_{2}$ internal tide energy flux. Solid lines indicate both glider and ADCP data coverage; dashed lines indicate that one or both of the datasets required extrapolation. Positive fluxes are down-slope and along-slope to the southeast.

where $p_{\text {surf }}^{\prime}$ is pressure perturbation at the surface due to the internal tide, determined by applying the baroclinicity condition for pressure,

$p_{\text {surf }}^{\prime}(t)=-\frac{1}{H} \int_{-H}^{0} p^{\prime}(z, t) \mathrm{d} z$.

Figure 3 shows potential density (Fig. $3 \mathrm{c}$ and d) and the $D_{2}$ component of vertical isopycnal displacement (Fig. 3e and f) for the $40 \mathrm{~h}$ analysis window. The amplitudes and phases of the $D_{2}$ component of $\xi$ are shown in Fig. $4 \mathrm{a}$ and $\mathrm{b}$.

\subsection{Baroclinic velocity}

For the same $40 \mathrm{~h}$ window, horizontal velocity perturbation is calculated,

$\boldsymbol{u}^{\prime}(z, t)=\boldsymbol{u}(z, t)-\overline{\boldsymbol{u}}(z)$

where $\overline{\boldsymbol{u}}(z)$ is the window-mean horizontal velocity profile. There are three spatial gaps in the time series: above $85 \mathrm{~m}$, between the ADCP and current meter (705-780 $\mathrm{m}$ including blanking distance), and from the current meter to the seabed $(785-800 \mathrm{~m})$. To obtain a full-depth time series, $\boldsymbol{u}^{\prime}$ is linearly interpolated between the ADCP and current meter, and extrapolated to the surface and the bottom using a nearest neighbour method. Baroclinic velocity is then calculated,

$\boldsymbol{u}_{\mathrm{bc}}^{\prime}(z, t)=\boldsymbol{u}^{\prime}(z, t)-\boldsymbol{u}_{\mathrm{bt}}^{\prime}(t)$, where $\boldsymbol{u}_{\mathrm{bt}}^{\prime}$ is barotropic velocity, assumed here to equal the depth-mean velocity, calculated as

$\boldsymbol{u}_{\mathrm{bt}}^{\prime}(t)=\frac{1}{H} \int_{-H}^{0} \boldsymbol{u}^{\prime}(z, t) \mathrm{d} z$.

The $D_{2}$ components of $\boldsymbol{u}_{\mathrm{bc}}^{\prime}$ and $\boldsymbol{u}_{\mathrm{bt}}^{\prime}$ are extracted using the same harmonic analysis method applied to $\xi$. Figure 3 shows barotropic (Fig. 3a and b) and baroclinic (Fig. 3c and d) velocities and the $D_{2}$ components of barotropic (Fig. 3a and b) and baroclinic (Fig. 3e and f) velocities for the $40 \mathrm{~h}$ analysis window. The amplitudes and phases of the $D_{2}$ component of $\boldsymbol{u}_{\mathrm{bc}}^{\prime}$ are shown in Fig. $4 \mathrm{a}$ and $\mathrm{b}$.

\subsection{Internal tide energetics}

Profiles of internal tide energy flux, available potential energy (APE), and horizontal kinetic energy (HKE) are calculated as

$\boldsymbol{F}(z)=\left\langle\boldsymbol{u}_{\mathrm{bc}}^{\prime}(z, t) p^{\prime}(z, t)\right\rangle$,

$\operatorname{APE}(z)=\frac{1}{2} \rho_{0} N^{2}(z)\left\langle\xi^{2}(z, t)\right\rangle$,

and

$\operatorname{HKE}(z)=\frac{1}{2} \rho_{0}\left\langle\boldsymbol{u}_{\mathrm{bc}}^{\prime 2}(z, t)\right\rangle$,

where $\langle\cdot\rangle$ denotes an average (mean) over an integer number of $M_{2}$ cycles and $\rho_{0}=1028 \mathrm{~kg} \mathrm{~m}^{-3}$ is a reference density. 
Table 1. Comparison between observed (glider and ADCP) $\mathrm{D}_{2}$ and modelled $M_{2}$ internal tide and surface tidal ellipse diagnostics. Modelled ellipse values are averaged (mean) over the 48 grid points in the area that contains all the glider dives deeper than $500 \mathrm{~m}$ (see Fig. 5d). The values in brackets are standard deviations. All bearings are anticlockwise from east.

\begin{tabular}{lrrrr}
\hline Variable & Units & Glider & ADCP & Model \\
\hline$F_{u}$ & $\mathrm{~kW} \mathrm{~m}^{-1}$ & 2.62 & 3.35 \\
$F_{v}$ & $\mathrm{~kW} \mathrm{~m}^{-1}$ & 3.31 & 3.00 \\
$F_{\text {mag }}$ & $\mathrm{kW} \mathrm{m}^{-1}$ & 4.23 & 4.50 \\
$F_{\text {dir }}$ & $\circ$ & 6.7 & & -3.2 \\
\hline $\mathrm{HKE}$ & $\mathrm{kJ} \mathrm{m}^{-2}$ & - & 5.50 & 4.99 \\
APE & $\mathrm{kJ} \mathrm{m}^{-2}$ & 1.73 & - & 2.24 \\
$\xi_{\text {max }}$ & $\mathrm{m}$ & 42.4 & - & 41.1 \\
$N_{\text {max }}^{2}$ & $\mathrm{~s}^{-2}\left(\times 10^{-5}\right)$ & 4.9 & - & 5.8 \\
\hline Semi-major axis & $\mathrm{cm} \mathrm{s}^{-1}$ & 15.5 & 14.7 & $21.1(2.2)$ \\
Semi-minor axis & $\mathrm{cm} \mathrm{s}^{-1}$ & 4.8 & 3.5 & $2.5(0.7)$ \\
Inclination & $\circ$ & 35.0 & 31.7 & $30.6(1.8)$ \\
Phase & $\circ$ & 331.4 & 329.6 & - \\
\hline
\end{tabular}

\section{Results}

Maximum $D_{2}$ vertical isopycnal displacement is $42 \mathrm{~m}$ and occurs at $565 \mathrm{~m}$ (Fig. 4a), within the main pycnocline. This is comparable with historic observations of a semidiurnal internal tide over the northern flank of the WTR. Sherwin (1991) analysed CTD data from a $17 \mathrm{~h}$ repeat station $(30 \mathrm{~min}$ between casts) that was $6.7 \mathrm{~km}$ east of the mooring (Fig. 1b) and determined maximum $D_{2}$ vertical isopycnal displacement to be 37 at $580 \mathrm{~m}$, again within the pycnocline. Here, almost all of the APE is contained within the pycnocline (Fig. 4c) because maximum $\xi$ occurs at a similar depth to maximum $N^{2}\left(4.9 \times 10^{-5} \mathrm{~s}^{-2}\right.$ at $\left.525 \mathrm{~m}\right) . D_{2}$ baroclinic velocity is maximum $\left(\approx 20 \mathrm{~cm} \mathrm{~s}^{-1}\right)$ near-bottom (Fig. 4a), as is HKE (Fig. 4c). Depth-integrated HKE and APE are 5.5 and $1.7 \mathrm{~kJ} \mathrm{~m}^{-2}$, respectively.

Both the across- and along-slope components of $D_{2}$ internal tide energy flux are maximum $\left(\approx 12.7 \mathrm{~kW} \mathrm{~m}^{-2}\right)$ nearbottom and go to zero at the depth of maximum $N^{2}$ (Fig. 4d), characteristic of a low-mode internal tide with a pycnocline in the lower half of the water column. Depth-integrated energy flux magnitude is $4.2 \mathrm{~kW} \mathrm{~m}^{-1}$, directed almost due east ( $7^{\circ}$ anticlockwise from east). In comparison, Sherwin (1991) estimated the $D_{2}$ mode-1 internal tide energy flux at the nearby CTD repeat station to be $4.7 \mathrm{~kW} \mathrm{~m}^{-1}$, but was unable to diagnose the direction.

\subsection{Model comparison}

In Fig. 5 the observations are compared with the regional tide model described by Hall et al. (2011). The model is a configuration of the Princeton Ocean Model (POM; Blumberg and Mellor, 1987) for the FSC and WTR region, initiated with typical late-summer stratification and forced at the boundaries with $M_{2}$ barotropic velocities (see Hall et al., 2011, for full details). Maximum $N^{2}$ in the model is slightly higher than observed (Table 1) but the vertical distribution of stratification is similar; the main pycnocline is between 500 and $600 \mathrm{~m} . M_{2}$ internal tide generation occurs within the model domain, driven by barotropic tidal currents across isobaths, and is diagnosed as positive barotropic-to-baroclinic energy conversion (Fig. 5b). The northern flank of the WTR is an area of energetic internal tide generation, up to $4 \mathrm{~W} \mathrm{~m}^{-2}$, and radiates an internal tide into the southern FSC. Modelled internal tide energy fluxes are spatially variable, but $>5 \mathrm{~kW} \mathrm{~m}^{-1}$ at some locations (Fig. 5a). The mooring was located east of the most energetic generation and up-slope of the largest energy fluxes.

For direct comparison, the model output is interpolated onto the exact location of the mooring (Table 1). The modelled $M_{2}$ internal tide energy flux is $6 \%-7 \%$ larger than the observed $D_{2}$ energy flux, but within $10^{\circ}$ of its direction. Maximum modelled vertical isopycnal displacement is $41 \mathrm{~m}$ (slightly smaller than observed) but is compensated by the higher maximum $N^{2}$ and results in modelled APE being $30 \%$ larger than observed; modelled HKE is $10 \%$ smaller than observed.

\subsection{Surface tidal ellipses}

As well as measuring potential density by the ADCP mooring, the glider is used to infer a second estimate of barotropic velocity. Harmonic analysis is used to extract the $D_{2}$ component of DAC velocity (all dives deeper than $500 \mathrm{~m}$ ) and compared to the $D_{2}$ component of $\boldsymbol{u}_{\mathrm{bt}}^{\prime}$ from the ADCP and current meter. Barotropic velocity is highest in the across-slope direction (maximum $15 \mathrm{~cm} \mathrm{~s}^{-1}$; Fig. 3a) and there is a very close match between the DAC and ADCP estimates (rms difference is $0.8 \mathrm{~cm} \mathrm{~s}^{-1}$ ). In the along-slope direction, where barotropic velocity is lower (maximum $0.5 \mathrm{~cm} \mathrm{~s}^{-1}$; Fig. 3b), the DAC estimate lags the ADCP estimate by $35 \mathrm{~min}$ but their amplitudes closely match (rms difference is $1.2 \mathrm{~cm} \mathrm{~s}^{-1}$ ). The resulting surface tidal ellipses have similar semi-major axis lengths and phases (Table 1) but the DAC estimate is less eccentric (more circular) and rotated $3^{\circ}$ anticlockwise (Fig. 5c). Compared with $M_{2}$ surface ellipses from the regional tide model described by Hall et al. (2011), both observational estimates are less eccentric and have shorter semi-major axes (Table 1; Fig. 5c). However, the inclination of observed and modelled ellipses are comparable, with their semi-major axes orientated across-slope. This is the orientation required to generate an energetic internal tide at the WTR. 

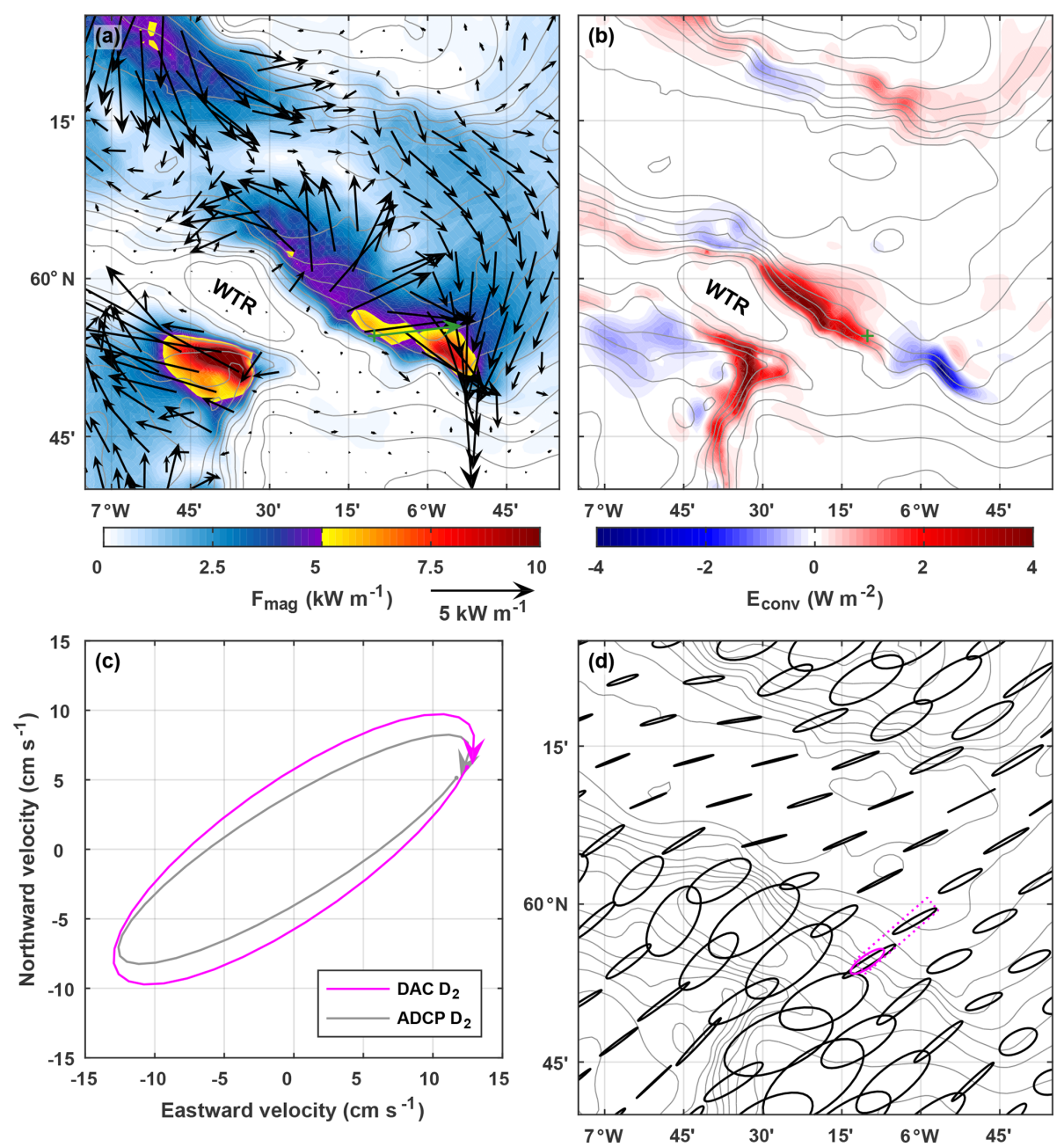

Figure 5. (a) Depth-integrated $M_{2}$ internal tide energy flux from the regional tide model described by Hall et al. (2011). Vectors are plotted every five grid points $(5 \mathrm{~km})$ in each direction. The underlying colour is the energy flux magnitude. The green vector is the depth-integrated $D_{2}$ internal tide energy flux observed at the green cross. (b) Barotropic-to-baroclinic $M_{2}$ energy conversion from the model. (c) $D_{2}$ surface ellipses calculated from glider-inferred DAC velocity (magenta) and ADCP-measured barotropic velocity (grey). (d) $M_{2}$ surface ellipses, every 10 grid points $(10 \mathrm{~km})$ in each direction, from the model. The magenta ellipse is calculated from DAC velocity and is representative of the area that contains all the dives deeper than $500 \mathrm{~m}$ (delineated by the dotted magenta line). The bathymetry contour interval is $100 \mathrm{~m}$.

\section{Glider sampling error}

The separation of spatial and temporal variability is a common problem when interpreting glider data due to their slow speed (Rudnick and Cole, 2011) and imperfect positioning. In this context, the inability of the glider to perfectly hold station by the ADCP mooring leads to error in the calculation of internal tide energy flux (Sect. 3) due to mis-sampling of the spatially and temporally varying density field. An understanding of this error is important for both mission planning and interpretation of results. Other missions along the European continental slope (e.g. Hall et al., 2017a) have shown that a glider operating as a virtual mooring by repeatedly diving to $1000 \mathrm{~m}$ around a fixed station can maintain a "watch circle" with a diameter of approximately $5 \mathrm{~km}$, i.e. all dives start and end within $2.5 \mathrm{~km}$ of the target location. The ability to do this is dependent on environmental conditions, particularly tidal and slope currents, but the lower limit is effectively set by the glide angle; a steep $45^{\circ}$ glide angle will result in around $2 \mathrm{~km}$ horizontal travel over a complete dive cycle to $1000 \mathrm{~m}$.

The size of the energy flux error is related to the length scale of the sampling cloud ( $d$, the diameter of the watch circle) and the horizontal wavelength of internal tide being measured $(\lambda)$. If $d \ll \lambda$ we can consider the glider data a fixed-point time series with no spatial-temporal aliasing, and so the error will be small. As $d$ increases the glider will increasingly sample density at the wrong phase of the internal tide and so the error will increase because the measured pressure perturbation $\left(p_{\text {Glider }}^{\prime}\right)$ will deviate from the pressure per- 


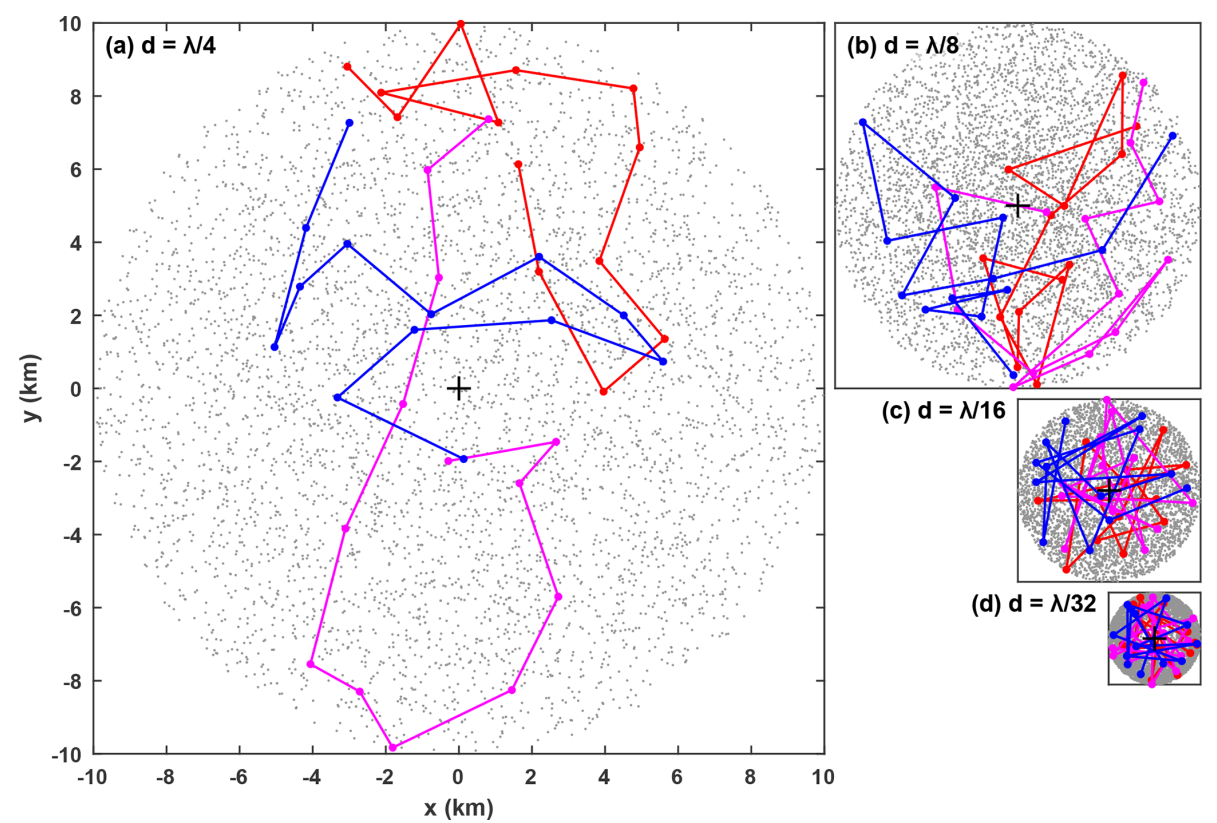

Figure 6. Pseudorandomly distributed glider paths within watch circles of diameters (a) $1 / 4 \lambda$, (b) $1 / 8 \lambda$, (c) $1 / 16 \lambda$, and (d) $1 / 32 \lambda$. The first 5000 surface locations are shown with a grey dot and the first three twelve-dive scenarios are shown in colour. The black cross is the location of the ADCP at the centre of the watch circle. All four panels are the same scale.

turbation at the $\mathrm{ADCP}\left(p_{\mathrm{ADCP}}^{\prime}\right)$, located at the centre of the watch circle. If $d \simeq \lambda$ the glider will sample density at random phases of the internal tide and so $p_{\mathrm{Glider}}^{\prime}$ and $p_{\mathrm{ADCP}}^{\prime}$ will be uncorrelated.

Here we use a Monte Carlo approach to estimate the energy flux error. Potential density in an idealized internal tide field is subsampled along pseudorandomly distributed glider paths contained within watch circles of varying diameters. The "true" depth-integrated energy flux at the ADCP, $\boldsymbol{F}_{\text {true }}=$ $\int_{-H}^{0}\left\langle\boldsymbol{u}_{\mathrm{bc}}^{\prime} p_{\mathrm{ADCP}}^{\prime}\right\rangle \mathrm{d} z$, is then compared with the "observed" depth-integrated energy flux, $\boldsymbol{F}_{\text {obs }}=\int_{-H}^{0}\left\langle\boldsymbol{u}_{\mathrm{bc}}^{\prime} p_{\text {Glider }}^{\prime}\right\rangle \mathrm{d} z$. In both equations $\boldsymbol{u}_{\mathrm{bc}}^{\prime}$ is baroclinic velocity at the ADCP. An idealized $M_{2}$ multi-mode internal tide field is created for a $1000 \mathrm{~m}$ deep water column with uniform stratification (Appendix A). The mode- 1 horizontal wavelength $(\lambda)$ is $80 \mathrm{~km}$ and mode-1 vertical isopycnal displacement is $50 \mathrm{~m}$, typical of mid-latitude shelf slope regions. Glider sampling is modelled as a group of twelve $1000 \mathrm{~m}$ dives (denoted here as a twelve-dive scenario) over $37 \mathrm{~h}\left(\approx 3 M_{2}\right.$ cycles $)$, within a watch circle of diameter $d$. Each dive is $2 \mathrm{~h} 50 \mathrm{~min}$ long, with $15 \mathrm{~min}$ at the surface between dives. Horizontal distance travelled during each dive cycle is between 1.5 and $4 \mathrm{~km}$ (typical of real glider missions), but there is no surface drift. The glider's path during each dive is determined by randomly selecting a start position within the watch circle then randomly selecting an end position $1.5-4 \mathrm{~km}$ away, but still within the watch circle. The start position of the following dive is the same as the end position. Potential density is linearly interpolated onto this pseudorandom glider path and the resulting density "observations" analysed using the method described in Sect. 3.1 to yield $p_{\text {Glider. }}^{\prime}$.

Nine cases are investigated, with $d$ ranging from $\lambda / 32$ $(2.5 \mathrm{~km})$ to $\lambda / 4(20 \mathrm{~km})$, and for each case 5000 different twelve-dive scenarios are simulated. A different random set of baroclinic mode phases is used for each scenario. Example pseudorandomly distributed glider paths for four cases are shown in Fig. 6. Energy flux relative error is defined as $\boldsymbol{F}_{\text {err }}=\left(\boldsymbol{F}_{\text {obs }}-\boldsymbol{F}_{\text {true }}\right) / \boldsymbol{F}_{\text {true }}$ so positive error indicates an overestimation and negative error indicates an underestimation. Similarly, APE relative error is defined as $\mathrm{APE}_{\text {err }}=$ $\left(\mathrm{APE}_{\text {obs }}-\mathrm{APE}\right.$ true $) / \mathrm{APE}_{\text {true }}$, where $\mathrm{APE}_{\text {true }}$ is "true" depthintegrated APE (calculated from $\xi_{\mathrm{ADCP}}$ ) and $\mathrm{APE}_{\mathrm{obs}}$ is "observed" depth-integrated APE (calculated from $\xi_{\text {Glider }}$ ).

\subsection{Single-scenario example}

A single twelve-dive scenario for the $d=\lambda / 4$ case is shown in Fig. 7 to highlight the impact of mis-sampling density on observed energy flux and APE. This is an extreme example, with all the glider dives $6-10 \mathrm{~km}$ from the ADCP (Fig. 7d), and features near-bottom internal tide intensification similar to that observed on the northern flank of the WTR. In this example, the error in measured density is maximum in the lower half of the water column (where $\xi_{\text {ADCP }}$ is up to $80 \mathrm{~m}$; Fig. 7a, b); the resulting $\xi_{\text {Glider }}$ underestimates $\xi_{\text {ADCP }}$ by up to $20 \mathrm{~m}$ and leads by up to $40 \mathrm{~min}$. Observed energy flux and APE underestimate true energy flux and APE over the majority of the water column (Fig. 7c); depth-integrated observed energy flux and APE underestimate depth-integrated 

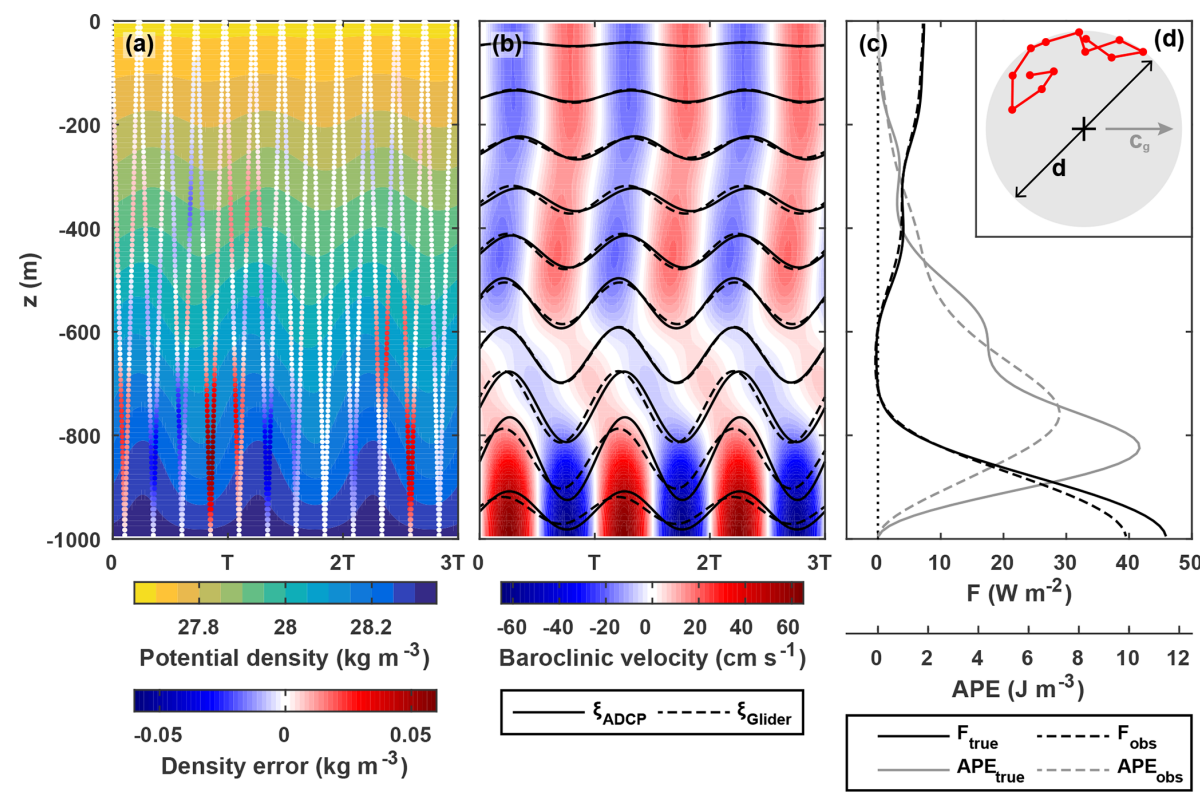

Figure 7. (a) Potential density for an idealized $M_{2}$ multi-mode internal tide overlaid with the error in measured density due to imperfect co-location of a glider and ADCP. The $x$ axis is time in $M_{2}$ cycles. Positive error indicates an overestimation of density. (b) Baroclinic velocity (colour) for the same idealized internal tide overlaid with vertical isopycnal displacement at the ADCP ( $\xi_{\text {ADCP, }}$ solid black lines) and calculated from measured density ( $\xi_{\text {Glider}}$, dashed black lines) every $100 \mathrm{~m}$. (c) "True" and "observed" internal tide energy flux (black) and available potential energy (grey). (d) Location of the pseudorandomly distributed glider path (red) relative to the ADCP (black cross). The diameter of the watch circle, $d=\lambda / 4$, where $\lambda=80 \mathrm{~km}$ is the mode- 1 horizontal wavelength. $c_{g}$ is the direction of tide propagation.

true energy flux and APE by $772 \mathrm{~W} \mathrm{~m}^{-1}\left(\boldsymbol{F}_{\text {err }}=-0.09\right)$ and $615 \mathrm{~J} \mathrm{~m}^{-2}\left(\mathrm{APE}_{\mathrm{err}}=-0.2\right)$, respectively.

\subsection{Energy flux error}

Histograms of $\boldsymbol{F}_{\text {err }}$ (0.005 wide bins) for four watch circle diameter cases are shown in Fig. 8a. The peaked distribution for the $d=1 / 32 \lambda$ case broadens with increasing watch circle diameter as well as becoming biased towards negative error. The negative bias results from two related mechanisms. Firstly, the amplitude of $\xi_{\text {Glider }}$ (and therefore $p_{\text {Glider }}^{\prime}$ ) is typically underestimated for large watch circles because the glider samples density with a broad range of phase shifts, causing spectral smearing and poor harmonic fits to $\xi$. Secondly, maximum energy flux occurs when $p^{\prime}$ and $\boldsymbol{u}_{\mathrm{bc}}^{\prime}$ are exactly in phase so any error in the phase of $p_{\text {Glider }}^{\prime}$, positive or negative, will also result in a negative bias.

$\boldsymbol{F}_{\text {err }}$ distributions for all nine watch circle diameter cases are shown in Fig. 8c, including the $99 \%$ and $95 \%$ confidence limits and the bias (median value). As watch circle diameter increases, the width of the confidence intervals increases and the bias becomes progressively more negative. For the $d=1 / 32 \lambda$ case, $\boldsymbol{F}_{\text {err }}$ is \pm 0.04 at the $99 \%$ limit and the bias is near zero $(-0.002)$. For the $d=1 / 4 \lambda$ case at the other extreme, $\boldsymbol{F}_{\text {err }}$ is 0 to -0.31 at the $99 \%$ limit and the bias is -0.1 .

\subsection{APE error}

Histograms of $\mathrm{APE}_{\text {err }}$ for four watch circle diameter cases are shown in Fig. 8b. Compared with $\boldsymbol{F}_{\text {err }}$, the distributions are broader and with a more negative bias for small watch circles. The broader distribution is explained by the error in $\xi_{\text {Glider }}$ being squared in Eq. (9). The negative bias is explained by the first mechanism described in Sect. 5.2. APE $E_{\text {err }}$ distributions for all nine watch circle diameter cases are shown in Fig. 8d. Similar to $\boldsymbol{F}_{\text {err }}$, the width of the confidence intervals increases and the bias becomes progressively more negative as watch circle diameter increases. For $d=1 / 32 \lambda$, $\mathrm{APE}_{\text {err }}$ is \pm 0.08 at the $99 \%$ limit and the bias is only -0.005 . For $d=1 / 4 \lambda, \mathrm{APE}_{\text {err }}$ is 0.02 to -0.33 at the $99 \%$ limit and the bias is -0.08 . Unlike $\boldsymbol{F}_{\text {err }}$, the bias converges towards a constant value for very large watch circles.

\section{Summary and discussion}

A novel approach to measuring internal tide energy flux using a co-located ocean glider and moored ADCP is tested using a dataset collected from the WTR in the North Atlantic. Gliders cannot perfectly hold station, even when operating as a virtual mooring, so error in the energy flux calculation due to imperfect co-location of the glider and ADCP is estimated by subsampling potential density in an idealized internal tide field along pseudorandomly distributed glider paths. 

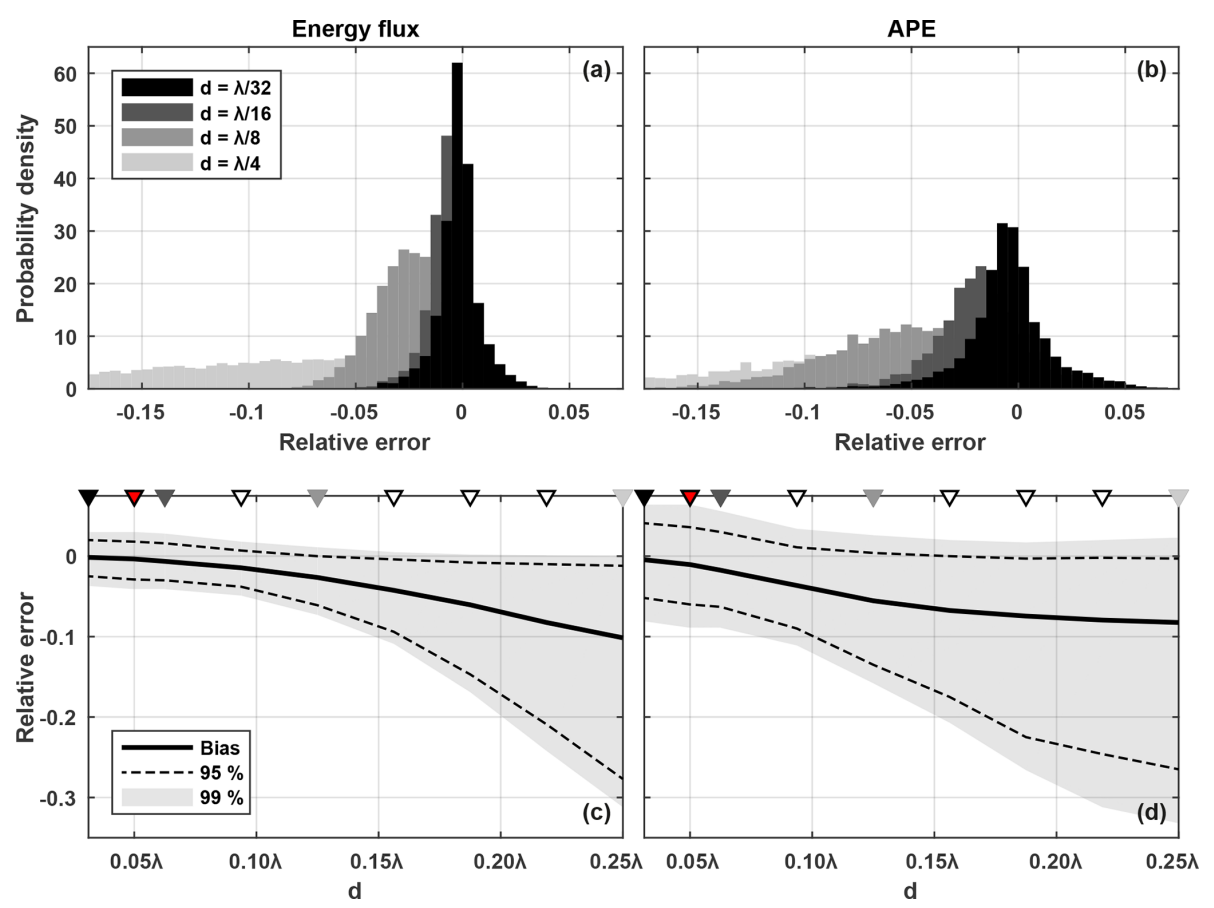

Figure 8. Histograms of (a) energy flux relative error and (b) APE relative error due to mis-sampling density in an idealized $M_{2}$ multi-mode internal tide field for the four watch circle diameter cases shown in Fig. 6. Positive error indicates an overestimation and negative error indicates an underestimation. Distribution of (a) energy flux relative error and (b) APE relative error against watch circle diameter, including the $99 \%$ and $95 \%$ confidence limits and the bias (median value). The four cases in panels (a) and (b) are indicated with black and grey triangles. The red triangle is the case most appropriate for the observations. The white triangles are four additional cases.

Table 2. Distributions of energy flux relative error $\left(\boldsymbol{F}_{\text {err }}\right)$ and APE relative error $\left(\mathrm{APE}_{\mathrm{err}}\right)$ for all nine watch circle diameter cases. $d / \lambda$ is watch circle diameter to mode-1 horizontal wavelength ratio. Positive error indicates an overestimation and negative error indicates an underestimation. The case most appropriate for the observations $(d / \lambda=0.05)$ is in bold.

\begin{tabular}{lrrrrr|rrrrrr}
\hline$d(\mathrm{~km})$ & $d / \lambda$ & \multicolumn{5}{c}{$\boldsymbol{F}_{\text {err }}$} & \multicolumn{5}{c}{ APE err } \\
\cline { 3 - 12 } & & $99 \%$ & $95 \%$ & Bias & $95 \%$ & $99 \%$ & $99 \%$ & $95 \%$ & Bias & $95 \%$ & $99 \%$ \\
\hline 2.5 & 0.03125 & -0.037 & -0.025 & -0.002 & 0.020 & 0.030 & -0.081 & -0.052 & -0.005 & 0.041 & 0.064 \\
$\mathbf{4 . 0}$ & $\mathbf{0 . 0 5}$ & $-\mathbf{0 . 0 4 1}$ & $-\mathbf{0 . 0 2 9}$ & $-\mathbf{0 . 0 0 4}$ & $\mathbf{0 . 0 1 8}$ & $\mathbf{0 . 0 3 0}$ & $-\mathbf{0 . 0 8 9}$ & $-\mathbf{0 . 0 6 0}$ & $-\mathbf{0 . 0 1 1}$ & $\mathbf{0 . 0 3 6}$ & $\mathbf{0 . 0 6 4}$ \\
5.0 & 0.0625 & -0.041 & -0.030 & -0.007 & 0.016 & 0.028 & -0.089 & -0.063 & -0.018 & 0.030 & 0.056 \\
7.5 & 0.09375 & -0.049 & -0.038 & -0.015 & 0.007 & 0.018 & -0.111 & -0.090 & -0.037 & 0.011 & 0.034 \\
10.0 & 0.125 & -0.073 & -0.061 & -0.027 & 0.000 & 0.011 & -0.158 & -0.135 & -0.056 & 0.004 & 0.026 \\
12.5 & 0.15625 & -0.109 & -0.094 & -0.043 & -0.004 & 0.005 & -0.207 & -0.175 & -0.068 & 0.000 & 0.020 \\
15.0 & 0.1875 & -0.169 & -0.147 & -0.061 & -0.008 & 0.002 & -0.266 & -0.225 & -0.075 & -0.003 & 0.017 \\
17.5 & 0.21875 & -0.242 & -0.209 & -0.083 & -0.010 & 0.001 & -0.312 & -0.246 & -0.080 & -0.002 & 0.020 \\
20.0 & 0.25 & -0.312 & -0.277 & -0.102 & -0.012 & 0.000 & -0.332 & -0.265 & -0.083 & -0.003 & 0.023 \\
\hline
\end{tabular}

If we consider the maximum acceptable energy flux error to be $0.1(10 \%)$, all the glider data must be contained within a watch circle with a diameter smaller than $1 / 8$ the mode1 horizontal wavelength of the internal tide. Energy flux is biased low and the negative bias increases with increasing watch circle diameter. If watch circle diameter is larger than $1 / 8$ the mode- 1 horizontal wavelength, the negative bias is more than $-0.03(3 \%)$ and all realizations within the $95 \%$ confidence interval are underestimates. When on-station over the WTR, the glider stayed within $2.5 \mathrm{~km}$ of the mooring so watch circle diameter $d=5 \mathrm{~km}$. The local $D_{2}$ mode- 1 horizontal wavelength $\lambda \approx 100 \mathrm{~km}$ so the $d / \lambda=0.05$ case (Table 2) is the most appropriate for the observations presented here. The observed energy flux is estimated to have a negative bias of only $-0.004(0.4 \%)$ and an error of less than \pm 0.03 $(3 \%)$ at the $95 \%$ confidence limit. This estimate does not include the effect of internal tide advection by the barotropic tide (Stephenson et al., 2016), which can lead to an additional 
negative bias if barotropic velocity amplitude is of a similar size to baroclinic phase speed. Over the WTR, $D_{2}$ mode- 1 phase speed is $\approx 2.2 \mathrm{~m} \mathrm{~s}^{-1}$ and barotropic velocity amplitude is $<0.2 \mathrm{~m} \mathrm{~s}^{-1}$ so we expect this effect to be negligible for our observations.

At mid-latitudes, $D_{2}$ mode-1 horizontal wavelength for a $1000 \mathrm{~m}$ deep water column is typically in the range 40$160 \mathrm{~km}$. The results presented here suggest energy flux error due to imperfect co-location can be reduced to an acceptable level $(10 \%)$ if the glider maintains a 5 to $20 \mathrm{~km}$ diameter watch circle. In the absence of strong tidal and slope currents, a well-trimmed glider diving to $1000 \mathrm{~m}$ with a relatively steep glide angle can usually maintain a watch circle with a diameter of $5 \mathrm{~km}$ or less, so energy flux error will typically be $<10 \%$. Where horizontal wavelengths are shorter, for example at lower latitudes or in shallower and less stratified water columns, a smaller watch circle will be required to maintain an acceptable level of error. In shallower water, smaller watch circles are generally achievable because horizontal travel over a complete dive cycle scales with dive depth. Diurnal internal tides have longer horizontal wavelengths so larger watch circles are acceptable. For mission planning, the mode- 1 horizontal wavelength of a tidal frequency $\omega$ can be estimated, $\lambda=2 \pi c_{1} / \sqrt{\omega^{2}-f^{2}}$, where $f$ is the inertial frequency and $c_{1}=N H / \pi$ is an approximation of mode- 1 eigenspeed. If the assumption of uniform stratification is not appropriate, $c_{1}$ can be calculated by solving the boundary value problem for a given $N(z)$ (Gill, 1982). Table 2 can then be used to estimate the energy flux bias and error that can be expected for a given value of $d / \lambda$.

Including the above estimate of error due to imperfect co-location, the observed depth-integrated $D_{2}$ internal tide energy flux over the northern flank of the WTR is $4.2 \pm$ $0.2 \mathrm{~kW} \mathrm{~m}^{-1}$. This is considerably larger than previous internal tide observations over the southeastern bank of the FSC: $0.2 \mathrm{~kW} \mathrm{~m}^{-1}(90 \mathrm{~km}$ northeast of the WTR; Hall et al., 2011) and $0.4-0.6 \mathrm{~kW} \mathrm{~m}^{-1}$ (105 km northeast of the WTR; Hall et al., 2017b), but small compared with some deepocean ridges, e.g. the Hawaiian Ridge (up to $33 \mathrm{~kW} \mathrm{~m}^{-1}$; Lee et al., 2006) and Luzon Strait (up to $41 \mathrm{~kW} \mathrm{~m}^{-1}$; Alford et al., 2011). More comparable to the WTR is the Mendocino Escarpment, where a ridge is orientated perpendicular to the continental slope and the observed energy flux is $7 \mathrm{~kW} \mathrm{~m}^{-1}$ (Althaus et al., 2003).
The $40 \mathrm{~h}$ co-located time series presented here is not long enough to resolve the internal spring-neap cycle. Peak neap tide occurred on yearday $153^{2}, 1$ day before the majority of the co-located time series. Assuming the internal tide is generated locally at the WTR, the surface and internal springneap cycles will be in phase. The observed $D_{2}$ energy flux is therefore representative of neap internal tide and so an underestimate of the true $M_{2}$ internal tide. This may somewhat explain the slight underestimate compared to the $M_{2}$-only regional tide model. Interestingly, the CTD time series used by Sherwin (1991) was recorded 2 days after peak spring tide so is more representative of spring internal tide. The fact that two observational estimates of $D_{2}$ vertical isopycnal displacement, $6.7 \mathrm{~km}$ apart and at different phases of the internal spring-neap cycle, are so similar implies that there are compensating spatial gradients in internal tide magnitude. The regional tide model shows the possible extent of these gradients and suggests that accurate siting of moorings is crucial for repeated long-term observations.

For future experiments, spatial gaps in the time series can be minimized with conductivity-temperature loggers and additional current meters on the mooring line. We have also shown that glider-inferred DAC can provide an accurate estimate of tidal current velocity that could be used to constrain barotropic velocity in the absence of full-depth data coverage by ADCPs and current meters. However, the major limitation of the dataset presented here is the short length of the co-located time series. Future glider missions will hold station by an ADCP mooring for several weeks to resolve the internal spring-neap cycle. Calculating $D_{2}$ internal tide energetics in a $36 \mathrm{~h}$ moving window will yield a time-varying energy flux that can be related to seasonal changes in stratification, advection by mesoscale eddies, spatial and temporal patterns in internal tide-driven turbulent mixing, and the resulting biogeochemical response.

Data availability. The Seaglider data were processed using the UEA Seaglider Toolbox (https://bitbucket.org/ bastienqueste/uea-seaglider-toolbox, last access: 9 February 2017) and are available from the British Oceanographic Data Centre (https://doi.org/10.5285/9373933d-48c1-5a37e053-6c86abc0e213; Wynn et al., 2019). The ADCP and acoustic current meter data are available from Marine Scotland (https://doi.org/10.7489/12217-1; Berx et al., 2019). Data analysis code is available on request from the corresponding author.

\footnotetext{
${ }^{2}$ We refer to time using yearday, defined as decimal days since midnight on 31 December 2016 (e.g. noon on 31 January 2017 is yearday 30.5$)$.
} 


\section{Appendix A: Idealized internal tide field}

An idealized $M_{2}$ multi-mode internal tide field is created for a $1000 \mathrm{~m}$ deep water column with uniform stratification $\left(N^{2}=6.1 \times 10^{-6} \mathrm{~s}^{-2}\right)$. Horizontal current velocity, $\boldsymbol{u}=$ $(u, v)$, and vertical isopycnal displacement, $\xi$, are defined by summing the first 10 baroclinic modes,

$$
\begin{aligned}
& u(x, y, z, t)=\sum_{n=1}^{10} u_{n} \sin \left(k_{n} x-\omega t-\phi_{n}\right) A_{n}(z), \\
& v(x, y, z, t)=\sum_{n=1}^{10} u_{n} \frac{f}{\omega} \cos \left(k_{n} x-\omega t-\phi_{n}\right) A_{n}(z),
\end{aligned}
$$

and

$$
\begin{aligned}
& \xi(x, y, z, t)= \\
& \sum_{n=1}^{10} u_{n} \sin \left(k_{n} x-\omega t-\phi_{n}\right) B_{n}(z) \frac{1}{\omega}\left(\frac{\omega^{2}-f^{2}}{N^{2}-\omega^{2}}\right)^{1 / 2},
\end{aligned}
$$

where $u_{n}$ and $\phi_{n}$ are the velocity amplitude and the phase of the $n$th baroclinic mode, respectively; $\omega=1.41 \times 10^{-4} \mathrm{~s}^{-1}$ is the $M_{2}$ frequency; and $f=1.26 \times 10^{-4} \mathrm{~s}^{-1}$ is the inertial frequency at $60^{\circ} \mathrm{N} . A_{n}(z)$ and $B_{n}(z)$ are the vertical structures of horizontal current velocity and vertical isopycnal displacement for each baroclinic mode, and are equivalent to $\cos (n \pi z / H)$ and $\sin (n \pi z / H)$, respectively, where $n$ is mode number. Horizontal wavenumber $k_{n}=\sqrt{\omega^{2}-f^{2}} / c_{n}$, where $c_{n}=N H / n \pi$, is an approximation of mode eigenspeed (Gill, 1982). Velocity amplitude decays with mode number, $u_{n}=u_{1} e^{-0.5(n-1)}$, where $u_{1}$ is the mode- 1 velocity amplitude. This decay rate results in a well-defined internal tide beam if velocity phase is approximately equal for each baroclinic mode. However, a different random set of baroclinic mode phases $\left(\phi_{n}\right)$ is used for each scenario simulated so internal tide beams are only apparent in a subset of scenarios. $u_{1}=0.28 \mathrm{~m} \mathrm{~s}^{-1}$ yields a mode- 1 vertical isopycnal displacement amplitude of $50 \mathrm{~m}$ but energy flux error and APE error are not sensitive to absolute amplitude. The timevarying potential density field is then

$\rho(x, y, z, t)=\bar{\rho}(z)+\frac{\rho_{0}}{g} N^{2} \xi$,

where $\bar{\rho}(z)$ is a background density profile with a vertical gradient equivalent to $N^{2}$. Barotropic velocity $\left(\boldsymbol{u}_{\mathrm{bt}}^{\prime}\right)$ and residual flow $(\overline{\boldsymbol{u}})$ are both zero so $\boldsymbol{u}_{\mathrm{bc}}^{\prime}=\boldsymbol{u}$. 
Author contributions. RH led the glider mission, analysed the colocated glider and ADCP dataset, and developed the method for estimating glider sampling error. BB lead the mooring deployment and processing of the ADCP data. GD processed and qualitycontrolled the glider data. The paper was written by RH with input from the other authors.

Competing interests. The authors declare that they have no conflict of interest.

Special issue statement. This article is part of the special issue "Developments in the science and history of tides (OS/ACP/HGSS/NPG/SE inter-journal SI)". It is not associated with a conference.

Acknowledgements. SG613 is owned and maintained by the UEA Marine Support Facility. The glider and ADCP mooring were deployed as part of the fourth Marine Autonomous Systems in Support of Marine Observations mission (MASSMO4; funded primarily by the Defence Science and Technology Laboratory) and the Marine Scotland Science Offshore Monitoring Programme. The cooperation of the captain and crew of NRV Alliance (CMRE, Centre for Maritime Research and Experimentation) and MRV Scotia (Marine Scotland) are gratefully acknowledged. The glider data were processed by Gillian Damerell, the ADCP data were processed by Helen Smith and Barbara Berx, and the acoustic current meter data were processed by Jennifer Hindson and Helen Smith. Assistance with glider piloting was provided by the UEA Glider Group.

Review statement. This paper was edited by Mattias Green and reviewed by two anonymous referees.

\section{References}

Alford, M. H., MacKinnon, J. A., Nash, J. D., Simmons, H., Pickering, A., Klymak, J. M., Pinkel, R., Sun, O., Rainville, L., Musgrave, R., Beitzel, T., Fu, K.-H., and Lu, C.-W.: Energy flux and dissipation in Luzon Strait: Two tales of two ridges, J. Phys. Oceanogr., 41, 2211-2222, https://doi.org/10.1175/JPO-D-11073.1, 2011.

Althaus, A. M., Kunze, E., and Sanford, T. B.: Internal tide radiation from Mendocino Escarpment, J. Phys. Oceanogr., 33, 15101527, 2003.

Baines, P. G.: On internal tide generation models, Deep-Sea Res., 29, 307-338, 1982.

Berx, B., Hindson, J., and Smith, H.: Moored data from NWZ-E monitoring site in the Faroe-Shetland Channel, Marine Scotland, UK, https://doi.org/10.7489/12217-1, 2019.

Blumberg, A. F. and Mellor, G. L.: A description of a three-dimensional coastal ocean circulation model, in: ThreeDimensional Coastal Ocean Models, Vol. 4, edited by: Heaps, N. S., American Geophysical Union, Washington, DC, 1-16, 1987.
Boettger, D., Robertson, R., and Rainville, L.: Characterizing the semidiurnal internal tide off Tasmania using glider data, J. Geophys. Res.-Oceans, 120, 3730-3746, https://doi.org/10.1002/2015JC010711, 2015.

Emery, W. J. and Thomson, R. E.: Data Analysis Methods in Physical Oceanography, Elsevier, Amsterdam, 2 Edn., 654 pp., 2001.

Eriksen, C. C., Osse, T. J., Light, R. D., Wen, T., Lehman, T. W., Sabin, P. J., Ballard, J. W., and Chiodi, A. M.: Seaglider: a long-range autonomous underwater vehicle for oceanographic research, IEEE J. Oceanic Eng., 26, 424-436, https://doi.org/10.1109/48.972073, 2001.

Frajka-Williams, E., Eriksen, C. C., Rhines, P. B., and Harcourt, R. R.: Determining vertical water velocities from Seaglider, J. Atmos. Ocean. Tech., 28, 1641-1656, https://doi.org/10.1175/2011JTECHO830.1, 2011.

Garau, B., Ruiz, S., Zhang, W. G., Pascual, A., Heslop, E., Kerfoot, J., and Tintoré, J.: Thermal lag correction on Slocum CTD glider data, J. Atmos. Ocean. Tech., 28, 1065-1071, https://doi.org/10.1175/JTECH-D-10-05030.1, 2011.

Gill, A. E.: Atmosphere-Ocean Dynamics, Academic Press, 662 pp., 1982.

Hall, R. A., Huthnance, J. M., and Williams, R. G.: Internal tides, nonlinear internal wave trains, and mixing in the Faroe-Shetland Channel, J. Geophys. Res., 116, C03008, https://doi.org/10.1029/2010JC006213, 2011.

Hall, R. A., Aslam, T., and Huvenne, V. A. I.: Partly standing internal tides in a dendritic submarine canyon observed by an ocean glider, Deep-Sea Res. Pt. I, 126, 73-84, https://doi.org/10.1016/j.dsr.2017.05.015, 2017a.

Hall, R. A., Berx, B., and Inall, M. E.: Observing internal tides in high-risk regions using co-located ocean gliders and moored ADCPs, Oceanography, 30, 51-52, https://doi.org/10.5670/oceanog.2017.220, 2017b.

Hopkins, J. E., Stephenson, G. R., Green, J. A. M., Inall, M. E., and Palmer, M. R.: Storms modify baroclinic energy fluxes in a seasonally stratified shelf sea: Inertialtidal interaction, J. Geophys. Res.-Oceans, 119, 6863-6883, https://doi.org/10.1002/2014JC010011, 2014.

IOC, SCOR, and IAPSO: The international thermodynamic equation of seawater - 2010: Calculation and use of thermodynamics properties, in: Intergovernmental Oceanographic Commission, Manuals and Guides, 56, p. 196, UNESCO, 2010.

Johnston, T. M. S. and Rudnick, D. L.: Trapped diurnal internal tides, propagating semidiurnal internal tides, and mixing estimates in the California Current System from sustained glider observations, 2006-2012, Deep-Sea Res. Pt. II, 112, 61-78, https://doi.org/10.1016/j.dsr2.2014.03.009, 2015.

Johnston, T. M. S., Rudnick, D. L., Alford, M. H., Pickering, A., and Simmons, H. J.: Internal tide energy fluxes in the South China Sea from density and velocity measurements by gliders, J. Geophys. Res.-Oceans, 118, 3939-3949, https://doi.org/10.1002/jgrc.20311, 2013.

Johnston, T. M. S., Rudnick, D. L., and Kelly, S. M.: Standing internal tides in the Tasman Sea observed by gliders, J. Phys. Oceanogr., 45, 2715-2737, https://doi.org/10.1175/JPOD-15-0038.1, 2015.

Kunze, E., Rosenfeld, L. K., Carter, G. S., and Gregg, M. C.: Internal waves in Monterey Submarine Canyon, J. Phys. Oceanogr., 32, 1890-1913, 2002. 
Lee, C. M., Kunze, E., Sanford, T. B., Nash, J. D., Merrifield, M. A., and Holloway, P. E.: Internal tides and turbulence along the 3000$\mathrm{m}$ isobath of the Hawaiian Ridge, J. Phys. Oceanogr., 36, 11651182, 2006.

Nash, J. D., Alford, M. H., and Kunze, E.: Estimating internal wave energy fluxes in the ocean, J. Atmos. Ocean. Tech., 22, 15511570, 2005

Pingree, R. D., Mardell, G. T., and New, A. L.: Propagation of internal tides from the upper slopes of the Bay of Biscay, Nature, 321, 154-158, 1986.

Queste, B. Y.: Hydrographic observations of oxygen and related physical variables in the North Sea and Western Ross Sea Polynya, PhD thesis, School of Environmental Sciences, University of East Anglia, 215 pp., 2014.

Rainville, L., Lee, C. M., Rudnick, D. L., and Yang, K.-C.: Propagation of internal tides generated near Luzon Strait: Observations from autonomous gliders, J. Geophys. Res., 118, 4125-4138, https://doi.org/10.1002/jgrc.20293, 2013.

Rudnick, D. L. and Cole, S. T.: On sampling the ocean using underwater gliders, J. Geophys. Res., 116, C08010, https://doi.org/10.1029/2010JC006849, 2011.

Rudnick, D. L., Johnston, T. M. S., and Sherman, J. T.: High-frequency internal waves near the Luzion Strait observed by underwater gliders, J. Geophys. Res., 118, 1-11, https://doi.org/10.1002/jgrc.20083, 2013.

Sharples, J., Tweddle, J. F., Green, J. A. M., Palmer, M. R., Kim, Y.-N., Hickman, A. E., Holligan, P. M., Moore, C. M., Rippeth, T. P., Simpson, J. H., and Krivtsov, V.: Spring-neap modulation of internal tide mixing and vertical nitrate fluxes at a shelf edge, Limnol. Oceanogr., 52, 1735-1747, 2007.
Sharples, J., Ellis, J. R., Nolan, G., and Scott, B. E.: Fishing and the oceanography of stratified shelf seas, Prog. Oceanogr., 117, 130-139, https://doi.org/10.1016/j.pocean.2013.06.014, 2013.

Sherwin, T. J.: Evidence of a deep internal tide in the FaeroeShetland channel, in: Tidal Hydrodynamics, edited by: Parker, B. B., John Wiley \& Sons, New York, 469-488, 1991.

Stephenson, G. R., Green, J. A. M., and Inall, M. E.: Systematic bias in baroclinic energy estimates in shelf seas, J. Phys. Oceanogr. 46, 2851-2862, https://doi.org/10.1175/JPO-D-15-0215.1, 2016.

Todd, R. E., Rudnick, D. L., Sherman, J. T., Owens, W. B., and George, L.: Absolute velocity estimates from autonomous underwater gliders equipped with Doppler current profilers, J. Atmos. Ocean. Tech., 34, 309-333, https://doi.org/10.1175/JTECH-D16-0156.1, 2017.

Wynn, R. B., Wihsgott, J. U., Palmer, M. R., Lichtman, I. D., Miller, P., Goult, S., Nencioli, F., Loveday, B. R., Jones, S., Inall, M. E., Dumont, E., Venables, E., Jones, O., Risch, D., Hall, R. A., Cauchy, P., Pierpoint, C., Doran, J., Mowat, R., and Damerell, G. M.: MASSMO 4 project ocean glider and autonomous surface vehicle data, British Oceanographic Data Centre, National Oceanography Centre, NERC, UK, https://doi.org/10.5285/9373933d-48c1-5a37-e0536c86abc0e213, 2019.

Zhao, Z., Alford, M. H., Lien, R.-C., Gregg, M. C., and Carter, G. S.: Internal tides and mixing in a submarine canyon with time-varying stratification, J. Phys. Oceanogr., 42, 2121-2142, https://doi.org/10.1175/JPO-D-12-045.1, 2012. 